\title{
Developing of a new scale for assessing the adherence to colchicine treatment in pediatric patients with FMF
}

\author{
S Yesilkaya, C Acikel*, BE Fidanci, B Sozeri, NA Ayaz, N Akıncı, S Kavukçu, G Özçelik, U Aydogan, S Ozenç, S Emre, \\ O Donmez, A Delibaş, S Yüksel, A Berdelli, H Poyrazoğlu, M Saldır, N Çakar, H Peru, S Bakkaloğlu, Y Tabel, O Sarı, \\ A Polat, G Basbozkurt, E Unsal, O Kasapcopur, F Gok, S Ozen, E Demirkaya
}

From 8th International Congress of Familial Mediterranean Fever and Systemic Autoinflammatory Diseases Dresden, Germany. 30 September - 3 October 2015

\section{Introduction}

Familial Mediterranean Fever (FMF) is a disease characterized by attacks and colchicine is the medication considered most effective in reducing the intensity and frequency of attacks. Adherence to the medication regiment is important not only to manage FMF symptoms, but also to prevent amyloidosis.

\section{Objective}

In this study, it is aimed to develop and assess the validity and reliability of the adherence scale for colchicine treatment in pediatric FMF patients.

\section{Methods}

This study was planned as a methodological study to development of scale for assessment of adherence to treatment of pediatric patients with FMF using colchicine treatment. Pediatric patients (2-18 ages) with FMF using colchicine at least 6 months and accepted to participate in the study constitute the sample of the study. "Data collection forms about the sociodemographic and medical information (demographic, clinical and laboratory findings) of patients", "adherence scale for colchicine in pediatric FMF patients" and "Morisky Medication Adherence Scale" were used as data collection instruments. If the patient was under 7 years old, his parents filled the forms.

\section{Results}

There were 150 patients with FMF enrolled for the validation of the study. The median age of the patients was
$11.11 \pm 4.02$ (min.2.74-max.17.99) and 48.7\% of them were male. The median of the attack frequency was $11,00 \pm 10,74$ (min. 0 -max 52 ) and $60.7 \%$ of the participants had irregular attacks.

For internal consistency, Cronbach's alpha was 0,728 for "adherence scale for colchicine in pediatric FMF patients". Also, there was a positive and significant correlation ( $\mathrm{r}: 0.843, \mathrm{p}$

\section{Conclusion}

Based on these results, using this scale for the purpose of the assessment and follow up of adherence to treatment of pediatric patients with FMF who use colchicine is recommended.

Published: 28 September 2015

doi:10.1186/1546-0096-13-S1-P109

Cite this article as: Yesilkaya et al:: Developing of a new scale for assessing the adherence to colchicine treatment in pediatric patients with FMF. Pediatric Rheumatology 2015 13(Suppl 1):P109. 